Ciencia y Sociedad, Vol. 46, No. 2, abril-junio, 2021 • ISSN (impreso): 0378-7680 • ISSN (en línea): 2613-8751

DOI: https://doi.org/10.22206/cys.2021.v46i2.pp123-139

\title{
IMPLICACIONES DIVERSAS A UN AÑO EN EL ENTORNO COVID-19 EN MÉXICO
}

\section{Implications diverse to one year in the covid-19 in Mexico}

\section{Eduardo Teófilo-Salvador}

Tecnológico Nacional de México/TESSFP, Estado de México. Toluca, México. ORCID: 0000-0001-8794-2938

Correo-e: mca.ts.eduardo2015@gmail.com

\section{Recibido: 12/1/2021 • Aprobado: 7/5/2021}

Cómo citar: Teófilo-Salvador, E. (2021). Implicaciones diversas a un año en el entorno COVID-19 en México. Ciencia y Sociedad, 46(2), 123-139. DOI: https://doi.org/10.22206/cys.2021.v46i2.pp123-139

\section{Resumen}

Actualmente aun con grandes avances científicos y tecnológicos, las enfermedades virales pueden contagiarse y propagarse a tasas muy elevadas, no permitiendo una protección y atención eficiente. El objetivo de esta investigación fue realizar una revisión de las implicaciones más sobresalientes que la COVID-19 ha generado en diversos sectores, a un año de los primeros casos en México. Primero fue necesario identificar como se propaga, con ello se revisaron efectos en diversos escenarios de la vida social en México, se revisaron propuestas de atención en escala gradual, que favorecen la reactivación económica, el regreso a los espacios públicos y con ello el regreso a la normalidad. Se obtuvo que, los comercios, el turismo y estadios son espacios con mayor probabilidad de contagio, pero espacios como las escuelas e iglesias pueden ser un ejemplo de prevención controlada y ordenada, aun reconociendo que, esta pandemia ha cambiado el actuar de la población que tiene las posibilidades de trasladar trabajo presencial en trabajo virtual, pero a costa del aislamiento. Se ha concluido que esta emergencia sanitaria ha dejado daños diversos en todos los sectores de la vida cotidiana, pero uno de los más preocupantes es que ha mostrado una desigualdad social.

Palabras clave: microeconomía; vida cotidiana; acciones.

\begin{abstract}
Currently, even with great scientific and technological advances, viral diseases can be contagious and spread at very high rates, not allowing efficient protection and care. The objective of this research was to conduct a review of the most outstanding implications that COVID-19 has generated in various sectors, from the personal, social and public spaces. It began by identifying some forms of propagation, with these effects in various scenarios of social life in Mexico were reviewed, some proposals for care were identified on a gradual scale, which favor economic reactivation, the return to public spaces and with it the return to everyday life. It was obtained that shops, tourism and stadiums are spaces with a higher probability of contagion, but spaces such as schools and churches can be an example of controlled and orderly prevention, even recognizing that this pandemic has changed the actions of the population that You have the possibility of transferring face-to-face work to virtual work, but at the cost of isolation. It has been concluded that this satin emergency has caused various damages in all sectors of daily life, but one of the most worrying is that it has shown social inequality.
\end{abstract}

Keyword: microeconomics; daily life; actions. 


\section{Introducción}

A finales de 2019, durante el 2020 y aun en 2021, a nivel mundial, ha surgido una de las pandemias más grandes de la época reciente; Hermi y García (2020) indican que se originó en Wuhan, China, presentándose los primeros casos el 1 de diciembre 2019. A partir de ahí el virus fue identificado como coronavirus zoonótico (Liu et al., 2020), similar al coronavirus del SARS y al coronavirus MERS, y este nombrado COVID-19. Mehta et al. (2020) mencionan que este virus tiene una mortalidad aproximada del $3.7 \%$ con respecto a la influenza, derivado de la dificultad respiratoria tal como un brote continuo de neumonía viral (Bai et al., 2020). Para atender la emergencia sanitaria, se han iniciado estudios de nuevas terapias, antivirales y vacunas, así como de recomendaciones en atención a la protección de otros sistemas del cuerpo humano tal como el cardiovascular durante el tratamiento para COVID-19 (Zheng et al., 2020). Se sugirieron varios medicamentos posibles y con ello de ensayos y fases de aplicación, adicionalmente se han tomado medidas sociales para reducir la propagación sugeridas y recomendadas por la Organización Mundial de la Salud (Organización Mundial de la Salud, OMS, 2020).

Anderson et al. (2020) indican que la velocidad de propagación inicial de la epidemia, su tiempo de duplicación o el intervalo en serie (tiempo promedio en que una persona infectada transmite la infección a otros) y la duración probable están influenciados por el tiempo desde la infección hasta que afecta a otros y la duración de la infección. Debido a lo anterior ha sido imposible rastrear y dar continuidad con precisión a casos positivos y sospechosos, por ello, una forma de aislamiento nacional ha sido el cierre de fronteras y la suspensión de clases, lo que generó una desaceleración de la economía y la disminución en las cadenas de suministro, la baja en precio de materias primas y la reducción del turismo.

Detrás de esta crisis sanitaria, hay una evidente crisis económica en el mundo, aunque se ha tomado como referencia la crisis económica y financiera de 2007-2009, pero los efectos pueden aproximarse a la depresión de la década de 1930 (Chesnais, 2020), aun cuando la Organización para la Cooperación y el Desarrollo Económico (OCDE), al inicio de la pandemia, estimaba un crecimiento de la economía mundial del $2.9 \%$. En América Latina, como el Caribe, o Venezuela con crisis humanitaria desde 2019 por propagación del sarampión, el impacto de la COVID-19 puede ser más devastador que en economías más desarrolladas como en Brasil o México (Rodríguez-Morales et al., 2020). Clavellina y Domínguez (2020) indican que las economías emergentes muestran un panorama no tan alentador, la debilidad financiera e institucional limita acciones, América Latina anticipa un incremento en el desempleo y pobreza, la caída del turismo, en el caso de México un menor crecimiento.

En México, el 27 de febrero un paciente dio prueba positiva y el 28 de febrero se confirmó el primer caso en el territorio nacional, con ello, la necesidad de preparar y promover acciones de políticas públicas para la población en general (Vivanco-Lira, 2020). Pero este virus se propagó rápido, afectando los sectores salud, social, económico, educativo, alimentario, industrial, entre otros. Según Servais (2020) indica que se prevé un aumento exponencial del subempleo, reducción de horas de trabajo y de salarios.

A pesar de las medidas implementadas, desde acciones individuales, familiares, comunitarias, locales, municipales, estatales y federales, la detección y aislamiento de casos, localización de contactos y cuarentena, así como el distanciamiento social y físico, y con ello la atención y reducción de futuros casos de contagio, no ha sido posible. Lo anterior debido a que la población en México depende del trabajo presencial y trabajo físico, con lo cual si la gente no perece por la enfermedad lo hará por falta de fuentes de suministro tal como alimentarios $\mathrm{y}$ de higiene. 
Existe mucha información referente al nuevo coronavirus COVID-19, según los enfoques de estudio, pero a la fecha el número de contagios continúa aumentando, se inician rebrotes, especialmente en épocas vacacionales como fin de año y Semana Santa, ya que no se cuenta con certeza de medios o formas de atención de la economía de los más vulnerables, quienes tienen que exponerse para generar ingresos y que esto ha sido una causa de no aislamiento y de no respeto a las indicaciones gubernamentales. En este contexto, el objetivo fue realizar una revisión de las implicaciones más sobresalientes que la COVID-19 ha generado en diversos sectores a un año de los primeros casos en México.

\section{Materiales y métodos}

Para entender la metodología, fue necesario realizar el siguiente diagrama general que mostrara las implicaciones que la pandemia ha generado desde el inicio y durante, tal como lo muestra la figura 1. En este contexto, se estructuró la investigación en: i) formas de propagación, ii) las implicaciones que conlleva y, con ello, iii) los cambios en la vida cotidiana. Asimismo, se muestran variaciones de coloración en la línea de tiempo desde el inicio hasta que se tenga un control, las cuales van de rojo, como de alto riesgo de contagio, naranja, amarillo y verde; un semáforo epidemiológico utilizado en México, pero que varía en función de la época del ańo y del comportamiento social, por ejemplo, la primera ola con el máximo pico en los meses de julio - agosto por desinformación y poca concepción sobre los riesgos, la segunda ola por las fiestas decembrinas, con pico máximo en enero, pero la diferencia entre estas más allá de los casos, es la aplicación del semáforo epidemiológico (naranja en segunda ola $=$ rojo en primera ola).

Figura 1. Principios aplicados para desarrollo de la metodología

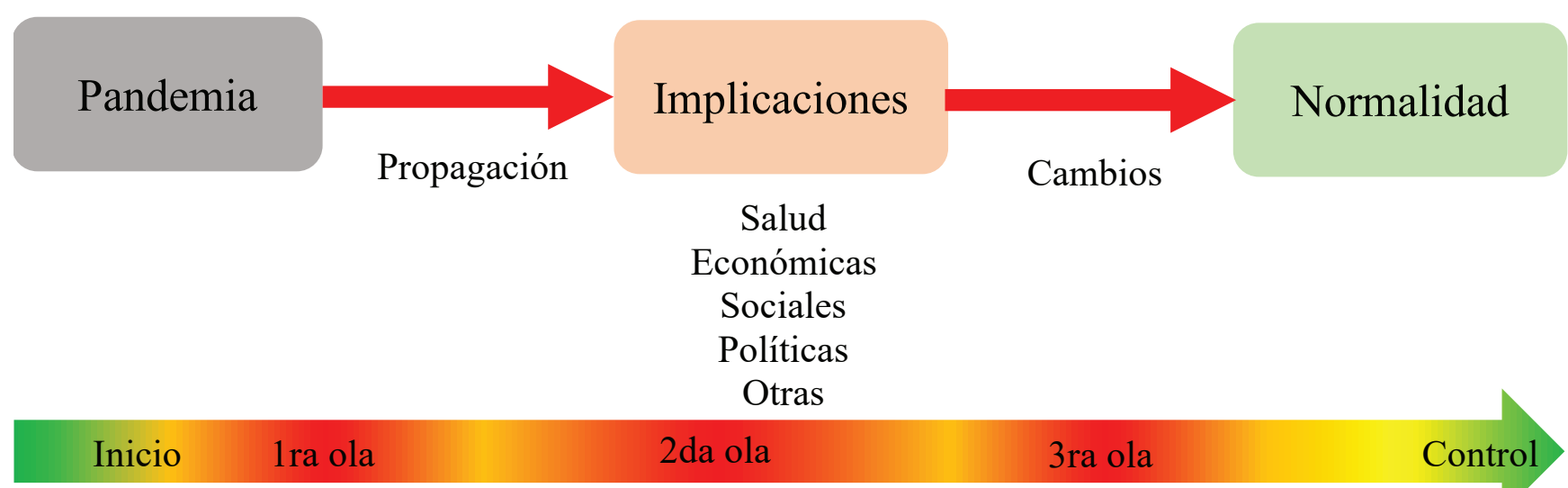


Para medir la importancia, es necesario reconocer que México cuenta con una población superior a los 126 millones de habitantes según el Censo de Población y Vivienda 2020, por tal se consultó la página coronavirus.gob.mx así como de los reportes diarios en televisoras nacionales, donde hasta el 15 de abril de 2021 en México se estimaban más de 2.3 millones de casos con más de 211 mil decesos y a nivel mundial se estimaban 140 millones de casos con más de 3 millones de muertes, de esta forma a finales de 2020 y principios de 2021 México se posicionaba entre los primeros cinco países con más casos en el mundo por debajo de Estados Unidos, India y Brasil.

\section{Interacciones de propagación}

Ramos (2020) indica que la transmisión de persona a persona y la diseminación del virus ha sido limitada debido a la baja reproducción del virus, por ello se reconoció que una de las principales formas de contagio es la exposición en zonas o áreas donde el virus se mantiene activo al salivar, por estornudos o al hablar, para lo cual se investigaron experiencias individuales, así como de documentación científica, recomendaciones de radio y televisión entre otros medios de comunicación, tal que estos indican no permanecer en espacio cerrados o poco ventilados. De acuerdo a lo anterior el contagio puede ser: $i$ ) pasivo, si el portador toma medidas preventivas, tal como distanciamiento o el aislamiento, o $i$ ) activo, como aquella persona con síntomas pero que no toma las medidas de distanciamiento, prevención o aislamiento. Pero además es necesario reconocer que los espacios físicos pueden generar que las condiciones anteriores ocurran en un estado: $i$ ) estático, cuando personas asisten algún sitio y se mantiene ahí hasta finalizar el evento, sin realizar movimientos o interacciones que generen altas tasas de contagio y, ii) dinámico, cuando personas interactúan de un punto a otro para alcanzar un fin dentro de un mismo evento, es decir, los movimientos y las condi- ciones no permiten un control de ello. Con estas consideraciones se propuso la tabla 1 de interacción-propagación.

Tabla 1. Interacción-Propagación de COVID-19 a través de persona-persona

\section{Manifestación Actuación $\begin{gathered}\text { Medio físico } \\ \text { (propagación) }\end{gathered}$

Activo $\quad \begin{gathered}\text { Estático } \\ \text { Dinámico }\end{gathered}$

Sintomático

Pasivo $\quad \begin{gathered}\text { Estático } \\ \text { Dinámico }\end{gathered}$

Activo $\quad \begin{gathered}\text { Estático } \\ \text { Dinámico }\end{gathered}$

Asintomático

Pasivo $\quad \begin{gathered}\text { Estático } \\ \text { Dinámico }\end{gathered}$

Los espacios físicos son uno de los principales factores que facilitan la propagación, por lo que para ello se analizó cómo son en algunos, como los muestra la figura 2. En el caso estático las personas se mantienen en un solo punto, la movilidad está regulada y es ordenada, para el caso dinámico, la población no sigue un patrón definido de movilidad, es disperso y desordenado. Un ejemplo, la población que acude con regularidad a tratamiento en hospitales o centros de salud, expuestos a una posible y potencial adquisición de la infección por los traslados, además de permanecer horas (Vega-Vega et al., 2020). 
Figura 2. Distribución, ordenación y movilización en diversos espacios públicos
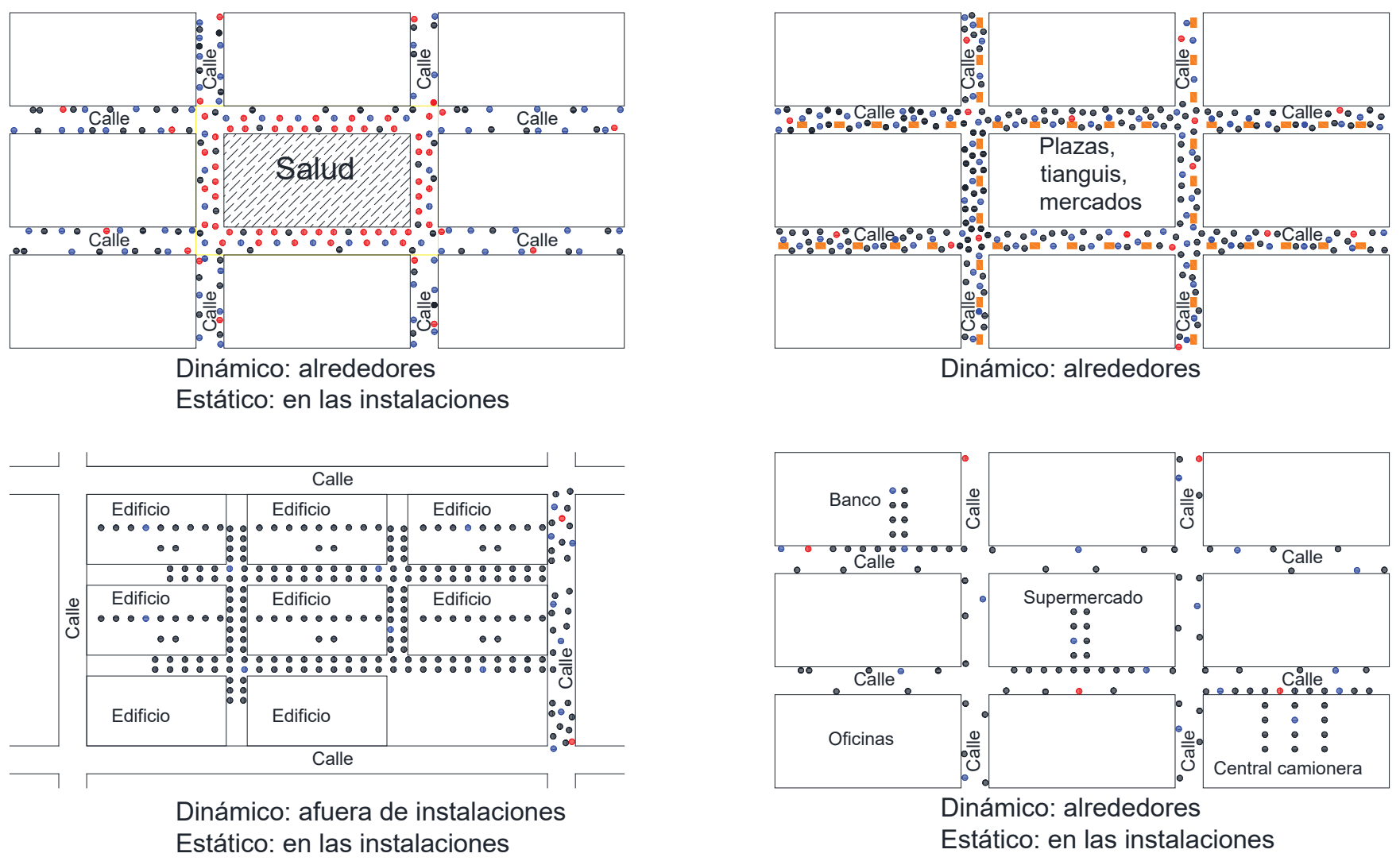

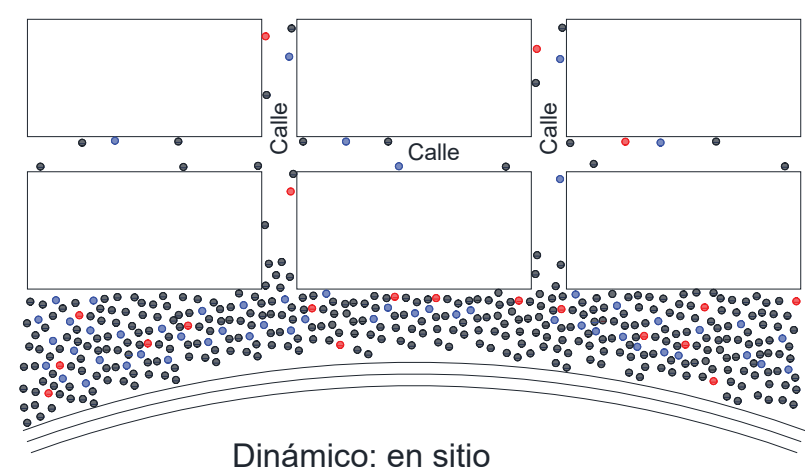

Dinámico: en sitio

- Asintomática-pasiva-dinámica
- Asintomática-activa-dinámica

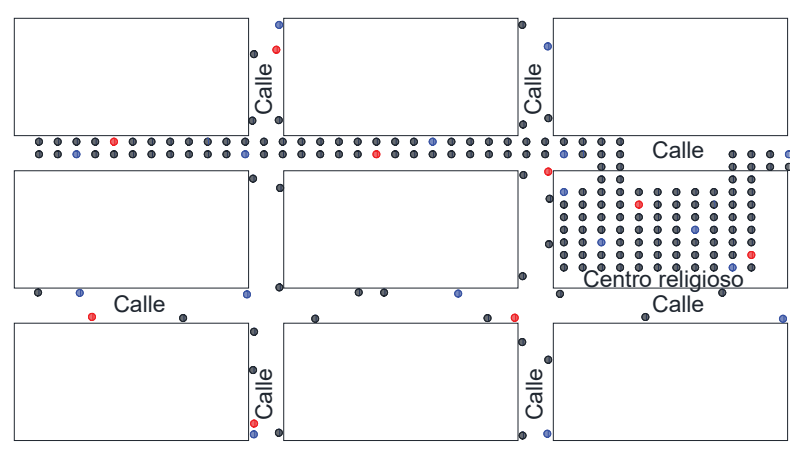

Dinámico: alrededores

Estático: en las instalaciones

- Sintomática-activa-dinámica
En la figura 2 se ha propuesto cómo es el comportamiento en diversos sitios y puntos de reunión, como hospitales, plazas, tianguis, oficinas, supermercados, playas y centros religiosos, y en todos los casos se ha considerado una movilidad sintomática-activa-dinámica como caso crítico al no respetar medidas de control o recomendaciones de distanciamiento. 


\section{Implicaciones sectoriales}

Una vez reconociendo la forma de propagación, fue necesario revisar las implicaciones que la pandemia ha generado y cómo las autoridades han tomado medidas y recomendaciones de aislamiento, distanciamiento y protección en caso de salir fuera de casa. En el caso de México, uno de los sectores más afectados ha sido la economía, ya que se manifiesta a través del comercio, actividades educativas, eventos religiosos, actividades deportivas, espectáculos, ambientales y servicios de turismo, entre otras. Por lo anterior, al aplicar la tabla 1 y la figura 2 se obtuvo la tabla 2 para evaluar cómo influye el espacio y el entorno, y con esto la valoración a criterio de la probabilidad de contagio, además de incluir un índice como ordenado y desordenado, controlado y no controlado, esto con la finalidad de proponer alternativas que pudieran influir a mediano plazo en la reactivación gradual de la economía y ocupación de espacios públicos.

Tabla 2. Sectores susceptibles a propiciar probabilidad de contagio

\begin{tabular}{|c|c|c|c|c|c|c|c|}
\hline Sector & Sitios & \multicolumn{2}{|c|}{ Propagación } & \multicolumn{2}{|c|}{ Actuación } & $\begin{array}{c}\text { Probabilidad } \\
\text { de contagio }\end{array}$ & Índice \\
\hline Salud & $\begin{array}{l}\text { Clínicas, } \\
\text { Hospitales }\end{array}$ & Estático & Dinámica & Pasivo & & Media & $\begin{array}{l}\text { Ordenado } \\
\text { Controlado }\end{array}$ \\
\hline Familiar & Hogar & Estático & & Pasivo & Activo & Medio & \\
\hline Comercio & $\begin{array}{l}\text { Tianguis, plazas, } \\
\text { mercados }\end{array}$ & & Dinámico & Pasivo & Activo & Alto & $\begin{array}{l}\text { Desordenado } \\
\text { No controlado }\end{array}$ \\
\hline Educación & $\begin{array}{l}\text { Escuelas, } \\
\text { Colegios, } \\
\text { Guarderías }\end{array}$ & Estático & & Pasivo & & Bajo & $\begin{array}{c}\text { Ordenado } \\
\text { No controlado }\end{array}$ \\
\hline $\begin{array}{l}\text { Telecomunica- } \\
\text { ciones }\end{array}$ & $\begin{array}{l}\text { Bancos, Servicio } \\
\text { Postal, CFE, } \\
\text { Oficinas de } \\
\text { Gobierno }\end{array}$ & Estático & & Pasivo & & Bajo & Ordenado \\
\hline Turismo/recreación & $\begin{array}{l}\text { Playas, } \\
\text { balnearios, } \\
\text { parques }\end{array}$ & & Dinámico & & Activo & Alto & $\begin{array}{l}\text { Desordenado } \\
\text { No controlado }\end{array}$ \\
\hline Religioso & $\begin{array}{l}\text { Iglesias, templos, } \\
\text { santuarios }\end{array}$ & Estático & & Pasivo & & Bajo & $\begin{array}{c}\text { Ordenado } \\
\text { No controlado }\end{array}$ \\
\hline Transporte & $\begin{array}{l}\text { Metro, } \\
\text { mexicable, tren, } \\
\text { autobús }\end{array}$ & & Dinámico & Pasivo & & Medio & $\begin{array}{c}\text { Ordenado } \\
\text { No controlado }\end{array}$ \\
\hline Ambiental & Campo & Estático & & & Activo & Bajo & Dispersión \\
\hline $\begin{array}{l}\text { Deportivo/ } \\
\text { espectáculos }\end{array}$ & $\begin{array}{l}\text { Estadios, } \\
\text { palenques, foros, } \\
\text { congresos }\end{array}$ & & Dinámico & & Activo & Alto & $\begin{array}{l}\text { Desordenado } \\
\text { No controlado }\end{array}$ \\
\hline
\end{tabular}




\section{Nueva normalidad vs. eventual normalidad}

La actual pandemia ha propiciado nuevas formas de convivencia, para lo cual se ha hecho uso del término "nueva normalidad", tal que la definición social obedece a nuevas formas y estilos de vida con cambios radicales a los que existían, sin embargo, hay que considerar que la humanidad desde sus inicios ha convivido con otros organismos y especies, contacto ser vivo-ser vivo, por lo que quizás el término más adecuado sería "eventual normalidad", ya que la ciencia está y ha hecho su parte en la búsqueda de vacunas o tratamientos eficaces, y una vez se logre esto un alto porcentaje de la humanidad retomará sus actividades ordinarias, las mismas que hacía antes de la pandemia. Por lo anterior se realizó un análisis de cómo puede entenderse esta terminología y cómo pudiera aplicarse en caso de no regresar a lo que era la humanidad antes de la aparición de la COVID-19.

\section{Resultados}

\section{Afectaciones por interacciones}

La epidemia no sigue un patrón definido, y esto debido a diversos factores como el ambiente, las concentraciones urbanas, la movilidad, además de las necesidades de cada centro poblacional, de los núcleos familiares y el entorno en el que se desarrollan. Pero la salud es el principal motor personal, social y global, tal como lo muestra la figura 3 , donde interactúan diversos escenarios, y esto obtenido de un análisis dinámico de movilidad en diversos sectores, ya que existe una clara relación y dependencia, haciendo notar que la COVID-19 es un tema multi e interdisciplinario ocupando a diversas áreas de investigación. A medida que decae la salud, se generan consecuencias como el aislamiento en lo personal y la pobreza en lo social, pero, contrariamente, desarrollo en el área de Ciencia y Tecnología, tal como se ha observado en la actualidad según el panorama local, nacional e internacional.
En la misma figura 3, se muestra cómo la salud lo mueve todo, así la dinámica social es la principal herramienta para el desarrollo, y se manifiesta en los grupos de personas que, a pesar de la contingencia, han salido a las calles en busca de una economía que les permita solventar sus necesidades básicas, incluso a costa de su salud. De esta forma, al verse afectada la salud, es posible que existan consecuencias personales, sociales y globales, por lo que son necesarios protocolos más estrictos y robustos en todos los sectores.

Figura 3. Interacción de escenarios diversos ante un riesgo de salud pública

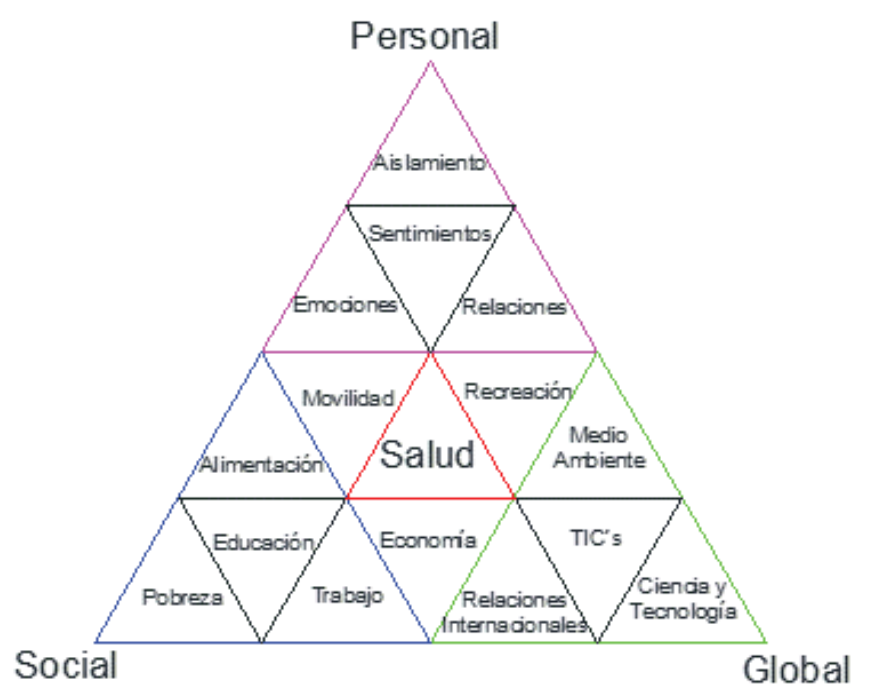

\section{Implicaciones diversas}

De acuerdo con lo anterior se reconocieron los servicios ofertados y con ello como se han propuesto alternativas de atención, de acuerdo con la CEPAL (2020) ya que, al no ser atendidos los impactos sociales, la crisis tendrá repercusiones negativas en la salud, educación, empleo y pobreza. Por consiguiente, se identificaron los siguientes escenarios que implícitamente involucran personas-contagio-economía. 


\section{A) Sector Salud}

Derivado de que la salud es el principal rubro de toda persona, y teniendo en cuenta que la COVID-19 varía de un organismo a otro, de las experiencias consultadas se expone el siguiente caso:

Tos seca con sensación de ahogamiento o atragantamiento 2 días, pareciera que todo está mejorando al automedicarse, $3^{\text {er }}$ día los cambios de temperatura y las actividades generan cansancio, debilidad hasta recaer en cama del $6^{\text {to }}$ al $10^{\text {mo }}$ día con malestar general, dolor de cabeza, sudoración nocturna, diarrea, ascos y falta de apetito, la tos seca no cesa, inicia dolor de pecho y abdomen al toser, dificultad para tomar agua, diagnóstico confirmado COVID-19 el día 11 mediante consulta médica privada, oxigenación al 91 $\%$ y bajando, es necesario iniciar tratamiento médico urgente para la infección en un estado de aislamiento, además de un estudio Tomografía computada de tórax para el día 13 para observar lesiones pulmonares con aspecto de vidrio despulido grado de severidad 14, donde la oxigenación está en $89 \%$. Reposo absoluto bocabajo, mínimos esfuerzos, concentración y pensamientos positivos todo el tiempo, revisión día 17 con oxigenación al $90 \%$, la diarrea ha dado tregua, ya hay apetito, el malestar general poco a poco desaparece, pero es necesario más medicamento. $93 \%$ de oxigenación día 21 , necesario seguir en reposo 7 días más y continuar medicando, donde el cuerpo poco a poco se recupera de los $7.5 \mathrm{~kg}$ perdidos de peso, pero aun con sudoración nocturna y dolores en la espalda, pecho y abdomen al bostezar, estornudar o con sensación de hipo. Día 35, los dolores descritos anteriormente son mínimos, el cuerpo ya responde a la energía suministrada por los alimentos y vitaminas, pero es necesario un estudio detallado para revisar posibles secuelas en algún órgano o tejido del cuerpo. Detección de tejidos musculares dañados en la espalda, calentura de pecho, aumento de estrés e insomnio los siguientes 40 días, necesario atender cada una de estas problemáticas mediante tratamientos médicos, terapias físicas y psicológicas para recuperar paulatinamente la salud, ya que lo difícil no ha sido vencer la enfermedad si no [sic] enfrentar las secuelas posCOVID-19. Valorar la vida a partir de cuidar la salud, no importa cómo, mediante deudas, prestamos o venta de bienes, pero es un hecho que la población que tiene esas facilidades está dispuesta a gastar más de los $\$ 21,320$ pesos mexicanos que ha costado este caso descrito desde el día 1 hasta el día 140, pero aun con la duda de ¿¿Dónde y cuándo fue el contagio?, ¿de 2 a 14 días antes de manifestarse los síntomas?, ¿y si me vuelvo a reinfectar?

La reinfección es posible, tal como lo ha expuesto Rodriguez-Morales et al. (2020), aunque son pocos los casos reportados hasta el momento. Otros casos consultados tuvieron un final no tan grato, por la desidia o por confundir la enfermedad con una gripa, no acudir al médico oportunamente, falta de recursos, temor de empeorar, o bien creer que la fiebre, dolor de garganta, presencia de cansancio se pasarían con los días, cosa que no sucede, más bien tienden a agravarse. Otros, intentando con remedios caseros como uso de miel o tés, pero no en todos los cuerpos funcionan adecuadamente, ya que cada uno responde de diversas formas, lo ideal es acudir al médico. Los medios de comunicación informan la saturación de hospitales por casos positivos, hay quienes optan por no asistir, por desconfianza o por temor a complicar la enfermedad como sucedió en el caso descrito anteriormente, aunque se cuente con instalaciones, equipos y personal especializado. Zamora y Palazuelos (2020) indican que es necesario la construcción de un mayor número de clínicas y hospitales, así como promover la cultura de la prevención y detección oportuna de enfermedades. 
De acuerdo con McKibbin y Fernando (2020), es necesario una mayor inversión en los sistemas de salud pública en todas las economías, en particular en las menos desarrolladas y con densidad poblacional alta, ya que un brote de esta magnitud colapsa muy rápido el sistema de salud, además de impactar gravemente en la economía global a corto plazo, afectando de manera principal a los más necesitados. Actualmente, ningún país estaba $100 \%$ preparado; escases de personal, insumos e instalaciones hacen la diferencia, por tal motivo, es importante fortalecer los sistemas de salud con un acceso universal, personal calificado y equipamiento, eliminando desigualdad de atención a grupos poblacionales (CEPAL, 2020), de igual modo la descentralización, ya que en muchas ciudades los servicios de salud especializados tienden a ser geográficamente centralizados, con ello la opción de estar en periferias urbano-semiurbano para mayor accesibilidad, respuesta rápida y espacios amplios.

\section{B) Sector SociallFamiliar}

Una de las recomendaciones más importantes ha sido no realizar manifestaciones grupales, motines, reuniones, ni asistir a eventos donde se concentre una gran cantidad de personas. De la forma anterior, esta emergencia sanitaria ha propiciado la unidad del núcleo de la sociedad "la familia", pero socialmente ha dejado una gran crisis económica, la cual como todas suelen durar más, por tal al igual que Nicolás (2020), es necesario tomar en cuenta y partir de la familia, con el apoyo a acceso a créditos, los cuales pueden estar en función de sus percepciones, número de integrantes y las necesidades a cubrir, pero con un pago no inmediato, sino cuando ellos se estabilicen, con ello se les está considerando a futuro en la reactivación económica, con lo cual tendrán poder y acceso adquisitivo para consumo. Además, es necesario considerar a la población más vulnerable, de bajos ingresos y del sector informal, con aplazamientos, exenciones y reprogramaciones de pagos (CEPAL, 2020).

\section{C) Sector Comercio}

Casi el 99 \% de las empresas de América Latina son micro, pequeñas o medianas y constituyen casi todos los sectores de la actividad económica (CEPAL, 2020), y con ello la vulnerabilidad financiera de las personas empleadas, ya que al aislarse generan reducción de sus ingresos, de ventas y el comercio, las cuales son actividades muy importantes en el México actual.

De acuerdo con un estudio realizado en el Tianguis-Plaza Ganadera Puente San Bernabé en Almoloya de Juárez, Estado de México en 2019, la afluencia peatonal fue del orden de 16 mil visitantes para un día saturado en una superficie de 42 hectáreas (densidad comercial del orden de $25 \mathrm{~m}^{2} /$ persona), si se considera que este tipo de comercios es un punto importante de contagios posibles, entonces plazas, tianguis o mercados en espacios reducidos como los instalados en calles, avenidas o explanadas poco amplias aumentan la posibilidad de propagación del virus, por el contacto cercano con personas diversas, y con ello se pierde la secuencia de casos confirmados sintomáticos y no sintomáticos al no existir un control de salud, social y comercial.

Se debe considerar una descentralización de espacios destinados actualmente al comercio (mercados, tianguis, plazas, etc.), planear, asignar y crear espacios abiertos para la comercialización de productos (en tiempo y espacio), tal como en comunidades o localidades rurales o campos de futbol en ciudades, para que con ello la población evite el traslado a cabeceras o centros municipales, lo que es muy común en municipios de México. En zonas urbanas es necesario distribuir este tipo de comercios a un solo costado de calles, con mayor libertad de tránsito, así como programar días específicos para cada colonia. De esta forma los habitantes evitan el uso de transporte colectivo en lo mínimo, se incentiva la economía y es posible identificar y controlar casos sospechosos de la enfermedad. Adicionalmente, la recolección de basura, desinfección y cierre del espacio por un par de días. 


\section{D) Sector Educación}

Según la CEPAL (2020) la interrupción de las actividades en centros educativos tendrá efectos significativos en el aprendizaje, especialmente de los más vulnerables, ya que actualmente no se cuenta al $100 \%$ con infraestructura de tecnologías digitales necesarias (acceso a computadora e internet), y con ello el aprendizaje a distancia no está garantizado. La educación en México no se debe de detener en ningún área profesional, así es necesario redistribuir el uso de las aulas, (espacio mínimo de $2 \mathrm{~m} \times 2 \mathrm{~m}=4 \mathrm{~m}^{2} /$ alumno), esto generara grupos reducidos, se deberá tomar en cuenta la apertura de más horarios, en el caso de matutino generar vespertino, en el caso de clases mixtas extender a días sábados, en el caso de materias cocurriculares o de formación final o no tan esenciales incluirlas en un plan virtual o remota, asignadas a uno o varios instructores, con ello se reduce la carga de asistencia en escuelas o centros educativos. Adicionalmente, identificar las rutas de entrada y salida en edificios escolares y planteles, así como promover diversos horarios para reducir aglomeraciones fuera de las instalaciones.

\section{E) Sector Telecomunicaciones/plataformas}

Para la afectación de la comunicación digital, Sánchez et al. (2020) expone que, en un estudio para profesorado de la Universidad Nacional Autónoma de México, para comunicación utilizan principalmente el correo electrónico, Facebook y WhatsApp, para trabajo académico Google Classroom, Moodle y Google Suite y para trabajo sincrónico Zoom, Google Hangouts y Skype, pero requieren disponibilidad de recursos digitales, recursos informativos, mejora en procesos y asesoría técnica.

Pero no en todos los casos se goza de instrumentos y medios, por tal es indispensable desarrollar plataformas con contenido innovador, actualizado y suficiente, así como atender regiones dispersas con escasos o nulos servicios de conectividad, telefonía y banda ancha, esto derivado de la disminución de la velocidad por el aumento exponencial en el tráfico de datos y la saturación de enrutadores Wi-Fi en el hogar (Telecom Advisory Services LLC, 2020), tal que uso del internet se limita a herramientas de comunicación y redes sociales por encima de app de salud, educativas y de comercio.

Además, es necesario estimular a los diversos sectores productivos en el uso de las Tecnologías de Información y Comunicación (TICs) y con ello la migración del trabajo. Con lo anterior, más la conectividad digitalizada generar la capacitación de los sectores sociales más vulnerables para que puedan enfrentar la desocupación (Telecom Advisory Services LLC, 2020).

\section{F) Sector Turismo/recreación}

De acuerdo con la Organización Mundial del Turismo, UNWTO (2020), este sector más que ninguna otra actividad económica con impacto social se basa en la interacción entre las personas, por tal razón han recomendado medidas para apoyar el sector, mitigar el impacto en el empleo, la liquidez y proteger a los más vulnerables. El mismo turismo y la recreación pueden ser el motor para recuperar otros sectores, tal como el alimentario, empleo, comercial a partir de nuevos modelos de empleo y consumo, además de que la diversificación evita la dependencia de una sola actividad o mercado.

En el contexto anterior, México juegan un rol importante, pero aún existen muchos centros turísticos centralizados y esto es debido a los productos y servicios que ofertan, por ejemplo balnearios, playas, parques acuáticos, parques recreativos y parques mixtos, que están relativamente posicionados generado el crecimiento de puntos específicos, de ahí que deba tomarse en cuenta que existen zonas con atractivo ecológico, cultural y social, que pueden ser ideales para generar movilización o turismo regional, de esta forma hacer partícipes a comunidades locales y grupos más vulnerables para proporcionarle los 
medios y las herramientas para desarrollar nuevos destinos y productos turísticos sobre todo en regiones rurales, marginadas y menos favorecidas.

\section{G) Sector Religioso}

La mayoría de los santuarios regionales y el nacional están centralizados en importantes núcleos urbanos, cuya influencia es un elemento muy importante para la atracción numerosa de campesinos modernos y tradicionales, tal que esto también puede ser un factor causal de la migración del campo a la ciudad (Cámara y Reyes, 1972). Aunque según Propin y Sánchez (2015) algunos santuarios católicos están distribuidos en México, otros están marcados en lugares específicos, lo que genera alta movilidad poblacional, peregrinaciones organizadas y turismo nacional y extranjero, y de acuerdo con Martínez (2016) estos santuarios pueden recibir anualmente 14 millones de turistas, de entre los cuales cuatro y cinco solo para el día de la Virgen de Guadalupe.

Actualmente, en México la religión mueve a millones de católicos y no católicos, por la Fe, devoción, agradecimiento y unión, tal que esto genera altas concentraciones de personas, como lo es en la Basílica de Guadalupe, la cual ha cerrado sus puertas del 10 al 13 de diciembre de 2020, para evitar grupos masivos de peregrinos. Las procesiones y peregrinaciones se han controlado, lo que ha favorecido el no coincidir en centros religiosos, como lo fue el cierre de panteones en los días de muertos.

\section{H) Sector Transporte}

La sobresatuación y las condiciones de los actuales servicios de transporte publico pueden ser un foco de propagación importante, si no se garantiza la higiene necesaria para los usuarios, además del sobrecupo, lo que no favorece a la sana distancia (Martínez et al., 2020). De acuerdo con la Dirección General de Salud Pública de la Comunidad de Madrid (2020), es necesario que las empresas o responsables de transporte público o privado provean y/o aseguren los medios y el conocimiento para asegurar la higiene en cualquier área de estaciones y vehículos del transporte público, tal como pasamanos, barrido y fregado, aspiración, así como desinfección.

En México es necesario tomar en consideración esta medida por largo tiempo, ya que las urbes concentran la más grande flota de vehículos automotores y de transporte, incluso millones de pasajeros hacen uso del sistema día a día, tal como los cinco millones de pasajeros que mueve el Sistema de Transporte Colectivo Metro de la Ciudad de México (González y Navarro, 1990). Adicional a las medidas de distanciamiento y ocupación en el transporte urbano al $50 \%$ o menos, es necesario incremento en las corridas para evitar aglomeraciones en interconexiones, estaciones o paradas autorizadas, pero además es necesario una adecuada desinfección por vuelta. Como medida adicional incentivar el uso de la bicicleta o bien caminar, para con ello evitar el uso de transporte público que pudiera generar mayor incertidumbre sobre el adecuado tratamiento de la higiene.

\section{I) Sector Deportivo y de espectáculos}

La pandemia del Covid-19 ha dejado claro que no es benéfico la concentración o aglomeraciones de personas, tal que esto supone un impacto económico mayor aun cuando es indefinida la suspensión de eventos deportivos, culturales y artístico (Hernández y Zevallos, 2020). La FIFA ha hecho recomendaciones para mitigar los dańos de la pandemia en el mundo del deporte, lo que ha traído consigo dificultades para solventar salarios, así como empleados (Gerbaudo, 2020), además de que esto ha generado la reducción y cancelación de actividades comerciales como producto de los eventos deportivos. La centralización de estadios, canchas, palenques, y todos los espacios destinados a eventos masivos generan una alta concentración de personas, y en la mayoría de los casos con exclusividad, por lo que puede ser necesario ocupar estadios, canchas 
y espacios aledaños o de provincia, así como delimitar butacas o espacios para los espectadores con la distancia adecuada, es decir, el acomodo tresbolillo. Además de establecer protocolos más estrictos en el uso de las instalaciones, tanto de los espectadores como de quienes suministran el servicio o entretenimiento.

\section{J) Sector Ambiental}

Actualmente, la misma pandemia ha traído consigo efectos positivos como lo es la mejora en la calidad del aire, debido a la reducción de vehículos automotores, y cierre parcial de industrias y fábricas, lo que ha permitido disminuir la emisión de gases como monóxido, dióxido de carbono y partículas suspendidas. Además de que especies animales de hábitat próximos a espacios urbanos, pueden curiosear por la ausencia de ruido, en busca de alimentos, así como por la proliferación de pastos y arbustos en parques y jardines públicos. Las playas limpias de basura, el mar generando vida y reproducción de especies animales y vegetales, por el momento libres de pesca, al igual que bosques y selvas por la caza. Incluso, la reducción de enfermedades virales y bacterianas por la disminución de movilidad en centros urbanos, así como una posible variación en la producción de alimentos a causa del sedentarismo, mientras estos no escaseen por pánico o alertas de desabasto. Posiblemente las poblaciones sustentables en las regiones más distantes sean las menos propensas a este virus, inclusive ni tengan noción de que el coronavirus existe.

\section{K) Política y gobierno}

En el caso de eventos de gobierno, la COVID-19 ha ocasionado la cancelación de eventos masivos de índole tradicional como el grito de independencia, los desfiles del 16 de septiembre y 20 de noviembre, los cuales años tras año movilizan a un gran número de espectadores nacionales e internacionales. Asimismo, se han reducido asambleas políticas, aunque no han sido del todo eficaz en escenarios donde la naturaleza ha dejado consecuencias graves, por lo que el desabastecimiento y la desesperación se han apoderado de los damnificados en busca de un apoyo económico o en especie, reduciendo distancias, cuidados y prevención.

Actualmente, el periodo electivo mayo-junio de 2021 para candidaturas políticas ha generado movilizaciones en diversos puntos del territorio nacional, bajo diversos intereses, pero que, si no se respetan las medidas sanitarias impuestas por el mismo gobierno, como la sana distancia y el uso de cubrebocas, en próximos meses pos-electorales puede presentarse o no un repunte de casos COVID-19, como una incierta tercera ola.

\section{Revisión de normalidad}

Este análisis muestra como la terminología está sujeta a una respuesta favorable para volver y continuar con la vida que no ha dejado ni dejará de ser normal, y todo gracias a la ciencia aplicada a una línea de tiempo. En la figura 4 se muestra el caso a) la normalidad sigue su curso y la pandemia de la COVID-19 solo es un punto en la historia de la humanidad como cualquier enfermedad que haya ocurrido antes, y que gracias a la ciencia han surgido soluciones, es decir, es un caso reversible. En la figura $4 \mathrm{~b}$ ), se muestra cómo se puede interpretar como nueva normalidad, en la cual existe un cambio brusco en la tendencia de la humanidad y esta no vuelve hacer la misma en ningún punto de la historia, es decir, un caso irreversible. Por lo que la palabra nueva normalidad implicaría que esta se instaló para quedarse y no regresar al pasado, esto es, hacer uso de nuevas medidas de control, nuevos protocolos, implementación de nuevas formas de adquisición de productos y de consumo. Sin embargo, ni en plena pandemia dichas medidas han tenido resultados $100 \%$ favorables, por lo que a corto plazo sería muy complicado cambiar la anterior forma de vida de toda la población mundial. 
Figura 4. La COVID-19 en la historia, a) tendencia reversible de normalidad antes y después, b) tendencia irreversible nueva normalidad después
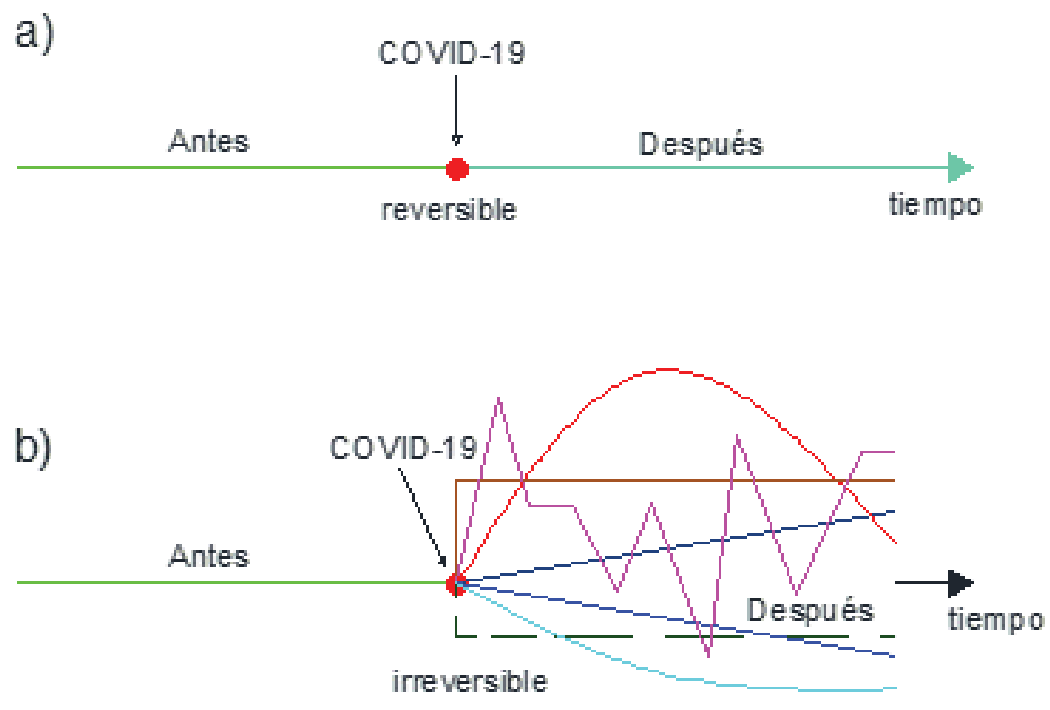

\section{Discusión}

Los sectores con mayor probabilidad de contagio son el comercio, el turismo y eventos deportivos masivos, esto por la cantidad de personas que asisten, además de que estas interactúan unas con otras de un punto a otro. Luego, los centros de salud y el transporte como unidades de transmisión, y por debajo, los referentes a educación, a servicios de telecomunicaciones y religiosos. Por ello, además de reabrir de forma gradual la economía puede ser prudente inicializar con ocupación del $25 \%, 50 \%$ y $100 \%$ según la tendencia de los registros de contagios diarios, la cual no es lineal, sino que sigue un comportamiento curvo, por ello los porcentajes anteriores. Además de considerar la posible ocupación alterna (trabajar medios tiempos, o medias semanas, o abrir horarios nocturnos para los sectores que lo requieran), para el sector educativo, que es uno de los más grandes de México, reprogramar los periodos vacacionales (adelantarlos) en periodos con proyección de altos contagios.

Es posible que algunas de las consideraciones presentadas previamente puedan garantizar una respuesta a la incertidumbre por la crisis y el tiempo de cuarentena, "el suministro de alimentos y artículo básicos", ya que no solo en México, sino, como en muchas partes, la población se precipitó a aprovisionarse de estos, lo que como todo genera demanda a corto plazo y con ello la escasez, produciendo alza de precios (Triviño-Gaviria et al., 2020).

Por lo anterior, si la población de pequeñas comunidades cuenta con servicio de mercado o tianguis un día a la semana, es posible reducir altas concentraciones en cabeceras municipales, traslados en transporte público, además de que con ello se reactiva la economía regional, la venta de productos de la región, el intercambio y la convivencia, la cual en estos días debido a la pandemia no ha sido posible por el aislamiento en casa.

Adicionalmente, la creación de espacios deportivos, parques o jardines propios de comunidades o intercomuniades generará empleo regional, comercio y con ello sana convivencia, con lo que es posible reducir la saturación de espacios o sitios turísticos. De esta forma es posible no paralizar del todo a la cadena 
de suministro, tal que los efectos de reactivación y adaptación serán más visibles a corto plazo, que para una economía totalmente paralizada. Además de que entre mayor tiempo se tenga de resguardo sin percepción monetaria, mayor serán las necesidades de insumos, lo que puede generar además de una crisis sanitaria y económica, una de seguridad y en el peor de los casos, una crisis humanitaria.

Según Clavellina (2020) diversos especialistas anticipan en 2021 una recuperación de la economía mundial, pero se requiere de recursos adicionales para atender la emergencia sanitaria, además de aplicar medidas que garanticen una efectiva reducción de contagios, tal como implementación de tratamientos médicos, evaluación y aplicación de vacunas y, en el mejor de los casos, la inmunización.

\section{Conclusiones}

Es urgente aplicar medidas más robustas en todos los sectores, ya que no es posible minimizar los efectos del coronavirus COVID-2019, sea de forma escalonada, paulatina o gradual, pero es necesario considerar medidas de descentralización de servicios que originalmente se ofertaban en sitios específicos y que generaban altas concentraciones de personas, con lo que aumenta la posibilidad de contagios.

La aplicación de medidas de reactivación económica no debe distinguir sectores de aplicación, para generar ganancias o beneficios particulares, estas medidas deben ser una muestra del interés por erradicar la desigualdad social.

Esta pandemia ha generado cosas benéficas, como la correcta higiene, la protección y prevención individual, aunque a costa de ello se vean sacrificadas otras acciones, pero que a mediano plazo traerán consigo beneficios más estables, y así solo veremos esta contingencia como un obstáculo, para medir que tan preparada está la humanidad para caer y volverse a levantar, y con qué celeridad lo hace.
La pandemia de la globalización ha permitido incluir ajustes en las formas de vida, como el uso de tecnologías y comunicación, pero ello puede generar el desplazamiento de los usos y costumbres de pueblos originarios que se han mantenido desde miles de años, y con ello la tentativa y forzosa desaparición al no adaptarse.

Las consideraciones anteriores pueden o no ser relevantes, sin embargo, a corto plazo es necesario implementar medidas para reactivar los sectores afectados y con ello a mediano plazo aplicar acciones emergentes, ya que la población no debe de vivir del miedo detrás de la puerta, la humanidad requiere de fortalezas para mitigar la COVID-19, y se pueden lograr con medidas estrictas, robustas, bien planeadas y aplicadas a inmediato plazo. Pero lo primordial generar conciencia en la población, educarla y disciplinarla, además de contar con sistemas de salud preparados ya que como ha documentado, la salud paraliza todo.

\section{Referencias}

Anderson, R., Heesterbeek, H., Klinkenberg, D. \& Hollingsworth, TD. (2020). How will country-based mitigation measures influence the course of the COVID-19 epidemic? The Lancet, 395, 931-934. Doi: https://doi.org/ 10.1016/S0140-6736(20)30567-5. https:// www.thelancet.com/journals/lancet/article/ PIIS0140-6736(20)30567-5/fulltext

Bai, Y., Yao, L., Wei, T., Tian, F., Jin, D-Y., Chen, L. \& Wang, M. (2020). Presumed asymptomatic Carrier transmisión of COVID-19. Letters, 323(14), 1406-1407. Doi: 10.1001/ jama.2020.2565

Cámara, B. F. \& Reyes, C. T. (1972). Los santuarios y las peregrinaciones, una expresión de relaciones sociales en una sociedad compleja: el caso de México. B. B. A. A. Boletín de Antropología americana, 35, 2, 29-45. https://www. jstor.org/stable/40975435?seq=1 
Chesnais, F. (2020). La economía mundial al principio de la gran recesión Covid-19. Herramienta Revista de debate y critica marxista, 28. https://www.herramienta.com.ar/articulo. php?id=3168

Clavellina, M. J.L. (2020). Política fiscal antela crisis del COVID-19 en América Latina. Notas Estratégicas, 87, 1-11. http://bibliodigitalibd. senado.gob.mx/handle/123456789/4846

Clavellina, M. J. L. \& Domínguez, R. M. I. (2020). Implicaciones económicas de la pandemia por COVID-19 y opciones de política. Notas Estratégicas, 81, 1-11. http://bibliodigitalibd. senado.gob.mx/handle/123456789/4829

Comisión Económica para América Latina y el Caribe, CEPAL. (2020). América Latina y el Caribe ante la pandemia del COVID-19. Efectos económicos y sociales. Informe Especial COVID-19, 1, 1-15. https://repositorio. cepal.org/bitstream/handle/11362/45337/6/ S2000264_es.pdf

Dirección General de Salud Pública de la Comunidad de Madrid. (2020). Pautas de desinfección de superficies y espacios habitados por casos en investigación, cuarentena, probables o confirmados de COVID-19. Viviendas, residencias, espacios de pública concurrencia (centros comerciales, supermercados, etc.) y transportes de viajeros. 4, 1-69. https://www.comunidad. $\mathrm{madrid} / \mathrm{sites} / \mathrm{default} / \mathrm{files} / \mathrm{doc} / \mathrm{sanidad} / \mathrm{samb} /$ protocolo_desinfeccion_de_superficies_y_ espacios_habitados.pdf

Gerbaudo, G. E. (2020). Aproximación a las directrices de la FIFA para abordar las consecuencias legales del COVID-19. Universidad Nacional de Rosario, 1-10. http://rephip.unr.edu.ar/ handle/2133/18020

González, G. O. \& Navarro, B. B. (1990). El metro de la Ciudad de México desarrollo y perspectiva. Momento Económico, 49, 4-9. http:// ru.iiec.unam.mx/2027/1/num49-articulo2_ Gonzalez-Navarro.pdf
Hermi, Z. M. \& García, A. M-B. (2020). El Covid-19 en España y sus primeras consecuencias. Espaco e Economia. Revista Brasileira de Geografia Economica. 17, 1-21. Doi: https:// doi.org/10.4000/espacoeconomia.10142

Hernández, C. M. \& Zevallos, T. C. (2020). Impacto económico del estado de emergencia por la pandemia de COVID-19 en los trabajadores y trabajadores de las artes visuales en el Perú (marzo 2020). 1-16. http://curadoresdelperu.org/wp-content/uploads/2020/04/ Impacto-COVID19_Artes-Visuales_ Peru\%CC\%81-2.pdf

Liu, Y., Gayle, A. A., Wilder-Smith, A. \& Rocklöv, J. (2020). The reproductive number of COVID-19 is higher compared to SARS coronavirus. Journal of Travel Medicine, 1-4. Doi: https://doi.org/10.1093/jtm/taaa021.

Martínez,S.J., Torres, R.C. \& Orozco, R.E.D. (2020). Características, medidas de política pública y riesgos de la pandemia del Covid-19. Dirección General de Investigación Estratégica, 1-25. http://bibliodigitalibd.senado.gob.mx/bitstream/handle/123456789/4816/Covid19\%20 $\% 28$ doc $\% 20$ de $\% 20$ trabajo\%29.pdf?sequen$\mathrm{ce}=1$ \&isAllowed $=\mathrm{y}$

Martínez, C. R. (2016). Turismo religioso en Los Altos de Jalisco (México. Un estudio de caso. En R. C. Martínez (Ed.), Santuarios, fiestas patronales, peregrinaciones y turismo religioso (pp. 107- 137). Universidad de Málaga y Universidad de Guadalajara, México. https://www. researchgate.net/publication/256096619_ Santuarios_fiestas_patronales_peregrinaciones_y_turismo_religioso

McKibbin, W. \& Fernando, R. (2020). The global macroeconomic impacts of COVID-19: seven scenarios. Centre for Applied Macroeconomic Analysis, Australina National University. 45 p. Doi: http://dx.doi.org/10.2139/ ssrn.3547729. https://papers.ssrn.com/sol3/ papers.cfm?abstract_id=3547729 
Mehta, P., McAuley, D. F., Brown, M., Sanchez, E., Tettersall, R., Manson J., et al. (2020). COVID19: consider cytokine storm syndromes and immunosuppression. Correspondence, 395, 1033-1034. Doi: https://doi.org/10.1016/ S0140-6736(20)30628-0 https://www. thelancet.com/journals/lancet/article/ PIIS0140-6736(20)30628-0/fulltext

Nicolás, S. A. (2020). Otra crisis: las soluciones al covid-19, no solo para salir a flote sino para volar. La Acción Social. Revista de Politica social y Servicios Sociales, 4(4), 1-5. https://socialmurcia.files.wordpress.com/2020/04/la-accic3b3n-social-4.4.pdf

Organización Mundial de la Salud (Word Health Organization). (2020). Coronavirus disease 2019 (COVID-19) situation report - 72. 13 p. https://www.who.int/docs/default-source/ coronaviruse/situation-reports/20200401sitrep-72-covid-19.pdf?sfvrsn=3dd8971b_2

Organización Mundial del Turismo, UNWTO. (2020). Apoyo al empleo y a la economía a través de los viajes y el Turismo. España, 1-45. https:// webunwto.s3.eu-west-1.amazonaws.com/ s3fs-public/2020-04/COVID19_Recommendations_ES.pdf

Propin, F. E. \& Sánchez, C. A. (2015). Santuarios católicos con magnetismo espiritual en México: una propuesta tipológica. Revista de Geografía Norte Grande, 64, 91-106. Doi: http://dx.doi. org/10.4067/S0718-34022015000200006.

Ramos, C. (2020). Covid-19: la nueva enfermedad causada por un coronavirus. Salud Pública de México, 62(2), 225-227. Doi: https://doi. org/10.21149/11276 https://www.medigraphic.com/pdfs/salpubmex/sal-2020/ sal202n.pdf

Rodriguez-Morales, A. J., Cardona-Ospina, J. A. \& Villamil-Gómez, W. E. (2020). Should we concern about reinfection in COVID19? Revista Infectio, 25(2), 77-78. http:// www.scielo.org.co/pdf/inf/v25n2/01239392-inf-25-02-77.pdf
Rodriguez-Morales, A. J., Gallego, V., Escalena-Antezana, J. P., Méndez, C. A., Zambrano, L. I., et. Al. (2020). COVID-19 in Latin America: The implications of the first confirmed case in Brazil. Travel Med Infect Dis., 1-4. Doi: 10.1016/j.tmaid.2020.101613

Sánchez, M. M., Martínez, H. A. M. P., Torres, C. R., Servín, M. A., Hernández, R.A. K., Benavides, L. M. A., Jaimes, V. C. A. \& Rendón, C. V. J. (2020). Retos educativos durante la pandemia de COVID-19: una encuesta a profesores de la UNAM. Revista Digital Universitaria, 1-23. https://www.revista.unam.mx/wp-content/ uploads/AOP.pdf

Servais, J. M. (2020). El COVID 19. ¿Qué nos dice la OIT? Universidad de Gerona, 1-5. http://www.cielolaboral.com/wp-content/ uploads/2020/04/oit_noticias_cielo_coronavirus.pdf

Telecom Advisory Services LLC. (2020). El estado de la digitalización de América Latina frente a la pandemia del COVID-19. Banco de Desarrollo de América Latina. En M. Agudelo (Ed.), Agencia Digital y del Observatorio CAF para el Ecosistema Digital. 40 p. América Latina y el Caribe. http://scioteca.caf.com/ handle/123456789/1540

Triviño-Gaviria, P., Castaño, S. \& Rubio, G. M. (2020). Política pública en tiempos del Covid19, entre la necesidad y la contingencia. Documentos Doctorado, 8, 1-20. http://www.fce. unal.edu.co/media/files/CentroEditorial/ documentos/documentosDoctorado/documentos-doctorado-8.pdf

Vega-Vega, O., Arvizu-Hernández, M., Domínguez-Cherit, J. G., Sierra-Madero, J. \& Correo-Rotter, R. (2020). Prevención y control de la infección por coronavirus SARS-CoV-2 (Covid-19) en unidades de hemodiálisis. Salud Pública de México, 62, 1-7. Doi: https://doi. org/10.21149/11330 
Vivanco-Lira, A. (2020). Predicting COVID-19 distribution in Mexico through a discrete and time-dependent Markov chain and an SIR-like model. 1-19. https://arxiv.org/abs/2003.06758

Zamora, S. I. \& Palazuelos, C. I. (2020). COVID-19 en México. Oportunidad para revisar pendientes en materia de salud pública. Visor Ciudadano, 69, 1-23. http://bibliodigitalibd.senado.gob. $\mathrm{mx} /$ handle/123456789/4831
Zheng, Y-Y., Ma, Y-T., Zhang, J-Y. \& Xie, X. (2020). COVID-19 and the cardiovascular system. Nature Reviews Cardiology, 17, 259-260. Doi: $10.1038 / \mathrm{s} 41569-020-0360-5$ 